\title{
Identifying severe community-acquired pneumonia: moving beyond mortality
}

\author{
James D Chalmers
}

Hospitalisations for community-acquired pneumonia (CAP) are increasing in the UK and internationally. ${ }^{1}$ Five to fifteen per cent of patients admitted to hospital with CAP die, and improvements in supportive care have maintained this death rate in the face of rising co-morbidity but have not resulted in substantial improvements. ${ }^{2}$ This lack of progress contrasts sharply with other medical emergencies such as acute myocardial infarction where there is an established pathway from recognition to early management and longterm care, which has brought substantial reductions in mortality. ${ }^{3}$

Kolditz et $a l^{4}$ report a new concept in CAP management, the idea of 'emergency CAP' to define patients at increased risk of early deterioration. In a large database of 3427 prospectively recruited patients with CAP from the multicentre CAPNETZ cohort only $173(5 \%)$ required mechanical ventilation and/or vasopressor support (MV/VS) or died within 7 days of admission. Twenty-seven per cent of such patients died within 30 days while in contrast only $2 \%$ of patients not requiring MV/VS in the first week of admission ultimately died. ${ }^{4}$

Importantly they demonstrated, as other authors have found in the past, that deterioration was largely predictable. ${ }^{5-7}$ The absence of any of the nine Infectious Diseases Society of America/American Thoracic Society (IDSA/ATS) criteria for severe pneumonia had a $99.7 \%$ negative predictive value and effectively excluded a poor outcome. ${ }^{4}$ This study also extended previous observations that the highest mortality in CAP is reserved for patients who deteriorate later in admission. ${ }^{8}$ Patients who required invasive MV/VS immediately on admission had a 30-day mortality rate of $24 \%$. In patients who did not require this intervention on admission but deteriorated later, 30-day mortality was $49 \% .^{4} \mathrm{MV} / \mathrm{VS}$ is used as the primary outcome in preference to intensive care unit (ICU) admission because it is more generalisable across healthcare systems. ${ }^{9}$ The UK, for example, has 3 ICU beds/100 000 population while

Correspondence to Dr James D Chalmers, College of Medicine, University of Dundee, Ninewells Hospital and Medical School, Dundee DD1 9SY, UK; jchalmers@dundee.ac.uk
Germany has 25/100 000. ${ }^{9}$ Therefore, ICU patients in Germany are likely to look very different to ICU patients in the UK, but definitions of respiratory failure and septic shock are robust across healthcare systems.

Following this study by Kolditz, we can conclude the following: a small but important proportion of patients will deteriorate in the first few days following admission with CAP. These patients can be readily identified by the presence of a small number of abnormal physiological variables with high sensitivity and late deterioration, particularly deterioration after day 4, carries a very poor prognosis. Identification of these patients for early intervention is essential. $^{4}$

So why did the authors look to study $\mathrm{MV} / \mathrm{VS}$ in the first week of admission instead of focusing on predictors of 30-day mortality, like virtually all CAP prognostic studies in the past 20 years?

Mortality from pneumonia is more complex than we might first think, and defining patients at high risk of mortality as 'severe CAP' seems intuitively correct but is problematic. A proportion of patients die from respiratory failure and septic shock but in fact patients dying in the ICU are a minority. In a large retrospective German study only $23.7 \%$ of patients that died had been admitted to an ICU, ${ }^{10}$ while a UK study found that $35 \%$ of patients with pneumonia had treatment restrictions indicated on admission that would prevent ICU admission, such as advanced directives or 'do not attempt resuscitation' orders. ${ }^{5}$ Pneumonia's reputation as the 'Old Mans Friend' is not entirely inaccurate. Up to $50 \%$ of deaths in the first 90 days after pneumonia are due to decompensated co-morbidities, particularly cardiovascular disease, rather than directly due to pneumonia. ${ }^{11}$ This presents a huge challenge for designing interventions to reduce mortality, because most interventions we intuitively feel might improve outcomes, such as earlier antibiotic administration or macrolide antibiotics and experimental treatments like corticosteroids or anti-inflammatory therapies, are only able to modify outcome in a subgroup of patients.

Therefore, defining severe CAP in a clinically useful way has been a major challenge and largely unsuccessful to date. The objective of Kolditz et al in studying predictors of MV/VS in the first week is therefore to identify those patients at the greatest risk, and also those patients in whom early resuscitation, appropriate treatment and new therapies have the potential to improve outcome.

Eighteen years after Fine et $a l^{12}$ developed the Pneumonia Severity Index (PSI), the archetypal clinical prediction tool for CAP, the literature on outcome prediction for pneumonia is vast. More than 30 different variations of prediction tools have been published, with some having achieved validation. ${ }^{13}$ Yet, until recently we have been some distance from a useful tool to identify the specific subgroup at high risk of needing MV/VS that we need to target to improve outcome.

The most widely recommended scores, PSI and the CURB65 score, were developed to predict 30-day mortality and primarily to guide discharge of patients from the emergency department and not to identify patients requiring MV/VS. ${ }^{13}{ }^{14}$ As a result, they are heavily weighted by age. This explains why CURB65, for example, has a sensitivity of less than $50 \%$ for $\mathrm{MV} / \mathrm{VS}$ in many studies, indicating that the majority of patients admitted to the ICU have 'mild' or 'moderate' CAP according to the score. ${ }^{13}$ This may also explain why the British Thoracic Society audits consistently show 'non-compliance' with recommendations to use oral monotherapy in mild CAP. More than 60\% received intravenous antibiotics and 50\% received combination antibiotics in 2009/ $2010 .^{15}$ While in some cases this may represent ignorance of the guidelines, both anecdotal and more quantitative efforts to understand this variation reveal an important gap between what clinicians recognise as severe pneumonia and what is identified by the scores leading to 'intelligent disobedience'.

Recognising that CURB65 and PSI were poorly adapted to guiding intensive therapy for these patients, the IDSA/ATS guidelines in 2007 devised a new set of criteria. ${ }^{16}$ These deliberately excluded age and focused exclusively on physiological variables (respiratory rate $>30 / \mathrm{min}, \mathrm{PaO}_{2} / \mathrm{FiO}_{2}$ ratio $<250$, multilobar infiltrates, confusion/disorientation, uraemia $>20 \mathrm{mg} / \mathrm{dL}$, leucopenia $<4000$ cells $/ \mathrm{mm}^{3}$, thrombocytopenia $<100000$ cells $/ \mathrm{mm}^{3}$, hypothermia $<36^{\circ} \mathrm{C}$ and hypotension requiring aggressive fluid resuscitation). ${ }^{14}$ The score was recently simplified to exclude leucopenia, hypothermia and thrombocytopenia, which are infrequent and do not add to the predictive value, ${ }^{17}$ a conclusion that 
Kolditz et $a l^{4}$ have now confirmed in an independent cohort. Validation studies suggest that this tool predicts mortality at least as well as the CURB65, with superior prediction of MV/VS. ${ }^{5-7} 17$

Development of clinical prediction tools involves an iterative process following derivation that includes external validation and then, the most important step, implementation into clinical practice to provide evidence that use of the tool can improve clinical outcomes in patients. Implementation of the PSI was shown in five studies of different designs to increase the proportion of emergency department patients safely discharged home. ${ }^{18}$ CURB65 has not been shown to improve patient outcomes in a prospective clinical study. Recently, a before and after evaluation study from Lim et al ${ }^{19}$ showed that implementation of an emergency department intervention in Singapore that included the use of the IDSA/ATS 2007 minor criteria resulted in a significant reduction in mortality.

More implementation data are needed but it seems that we now have a prediction tool that can genuinely predict both the critically important population with 'emergency CAP' and patients at high risk of death. It is more simple than the PSI, and lacks some of the weaknesses of CURB65. Crucially, we have some data that implementing it into clinical practice can improve targeting of early resuscitation and improve outcomes, although more methodologically robust data would be welcome.

Future studies should follow the model established here by Kolditz et al and consider MV/VS in preference to mortality as the gold standard to define severe CAP. For clinical practice, risk prediction tools can be very useful, particularly for less experienced physicians working in emergency departments and I agree with Kolditz et al that the IDSA/ATS minor criteria increasingly appear the most useful to complement clinical judgement.

Competing interests None declared.

Provenance and peer review Commissioned; internally peer reviewed.

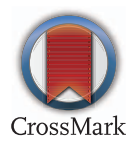

To cite Chalmers JD. Thorax 2015;70:515-516.

Published Online First 15 April 2015

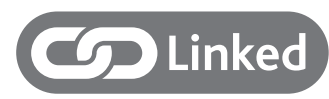

- http://dx.doi.org/10.1136/thoraxjnl-2014-206744

Thorax 2015;70:515-516.

doi:10.1136/thoraxjnl-2015-207090

\section{REFERENCES}

1 Trotter CL, Stuart JM, George R, et al. Increasing hospital admissions for pneumonia, England. Emerg Infect Dis 2008;14:727-33.

2 Welte T, Torres A, Nathwani D. Clinical and economics burden of community-acquired pneumonia among adults in Europe. Thorax 2012;67:71-9.

3 Ewig S, Torres A. Community-acquired pneumonia as an emergency: time for an aggressive intervention to lower mortality. Eur Respir J 2011;38:253-60.

4 Kolditz M, Ewig S, Klapdor B, et al. Community-acquired pneumonia as medical emergency: predictors of early deterioration. Thorax 2015;70:551-8.

5 Chalmers JD, Taylor J, Mandal P, et al. Validation of the IDSA/ATS minor criteria for ICU admission in community-acquired pneumonia patients without major criteria or contraindications to ICU care. Clin Infect Dis 2011;53:503-11.

6 Phua J, See KC, Chan YH, et al. Validation and clinical implications of the IDSA/ATS minor criteria for severe community-acquired pneumonia. Thorax 2009;64:598-603.
7 Brown $S M$, Jones BE, Jephson AR, et al. Validation of the Infectious Disease Society of Americal American Thoracic Society 2007 guidelines for severe community-acquired pneumonia. Crit Care Med 2009;37:3010-6.

8 Restrepo MI, Mortensen EM, Rello J, et al. Late admission to the ICU in patients with community-acquired pneumonia is associated with higher mortality. Chest 2010;137:552-7.

9 Wunsch $H$, Angus DC, Harrison DA, et al. Variation in critical care services across North America and Western Europe. Crit Care Med 2008;36:2787-93.

10 Bauer TT, Welte T, Strauss R, et al. Why do nonsurvivors from community-acquired pneumonia not receive ventilator support? Lung 2013;191: 417-24.

11 Mortensen EM, Coley CM, Singer DE, et al. Causes of death for patients with community-acquired pneumonia: results from the Pneumonia Patient Outcomes Research Team cohort study. Arch Intern Med 2002;162:1059-64.

12 Fine MJ, Auble TE, Yealy DM, et al. A prediction rule to identify low-risk patients with community-acquired pneumonia. N Eng/ J Med 1997;336:243-50.

13 Chalmers JD, Mandal P, Singanayagam A, et al. Severity assessment tools to guide ICU admission in community-acquired pneumonia: systematic review and meta-analysis. Intensive Care Med 2011;37: 1409-20.

14 Chen JH, Chang SS, Liu JJ. Comparison of clinical characteristics and performance of pneumonia severity score and CURB65 among younger adults, elderly and very old subjects. Thorax 2010;65:971-7.

15 Lim WS, Woodhead M. British Thoracic Society adult community-acquired pneumonia audit 2009/10. Thorax 2011;66:548-9.

16 Mandell LA, Wunderink RG, Anzueto $A$, et al. Infectious Disease Society of American/American Thoracic Society consensus guidelines for the management of community acquired pneumonia in adults. Clin Infect Dis. 2007;44:S27-72.

17 Salih W, Schembri S, Chalmers JD. Simplification of the IDSA/ATS criteria for severe communityacquired pneumonia. Eur Respir J 2014;43:842-51.

18 Chalmers JD, Akram AR, Hill AT. Increasing outpatient treatment of mild community-acquired pneumonia: systematic review and meta-analysis. Eur Respir J 2011;37:858-64.

19 Lim HF, Phua J, Mukhopadhyay A, et al. IDSA/ATS minor criteria aid pre-intensive care unit resuscitation in severe community-acquired pneumonia. Eur Respir J 2014;43:852-62. 